\title{
Status of Sodium Nitrite in Meat and Meat Products Available in the Market of
}

\author{
Kathmandu, Nepal.
}

\section{HARERAM PRADHAN*, SABITRI POUDEL, HUMA BOKKHIM, KRISHNA PRASAD RAI, SANJEEV KUMAR KARN}

\author{
Department of Food Technology and Quality Control, Kathmandu Nepal.
}

\begin{abstract}
Sodium nitrite was determined in 64 meat and meat products available in National Food and Feed Reference Laboratory from July 2017 to June 2018 following the AOAC (2016). None of the samples exceeded the Government of Nepal and India standard (200 ppm) and approximately five percent of the total samples had crossed the European Union standard (150ppm). Highest range (1.49-165.72 ppm) of sodium nitrite was found in chicken sausages and lowest (Not detected-55.83 ppm) in miscellaneous products (meat pickle, mo:mo, kebab, dried meat, and claws).Chicken and buff sausages were spiked at 50, 100 and 200 ppm level and the recovery were found to be 84.32, 94.97, 89.97 and 99.84, 104.36, 105.99\% respectively. Overall recovery were significantly higher $(p=0.000)$ in buff sausage $(103.40 \pm 3.57 \%)$ than in chicken sausage $(89.75 \pm 4.79 \%)$ at $5 \%$ level of significance. Sodium nitrite in the quality control sample was found to be $162.5 \pm 1.08$ ppm which was within the range (138226pm) given by the supplier.
\end{abstract}

Keywords: Sodium nitrite, ppm, recovery, limit of detection, limit of quantification

\section{Introduction}

Meat and meat products are one of the major food products for human. Consumption of meat and meat products in Nepal has been increasing day by day. From July 2014 to June 2015, 879501 metric tons of meat was consumed in Nepal (CBS, 2015). The reasons behind the increased in consumption are increase in per-capita income, fast growing urbanization, and readily availability of meat and meat products. Besides consumption of meat itself, consumption of different meat products is also increasing day by day. Different kinds of meat products such as: sausages, ham, bacon, dried meat, meat pickles, kebab, meat balls, meat fingers, patty etc. are now readily available in the Nepali market.

Among the different ingredients added in meat products, sodium nitrite is used relatively in small quantity as a nitrite curing salt during the production of meat products to produce the desired pickling red color (Belitz, Grosch, \& Schiebierle, 2009). Nitrite combines with myoglobin to give stable nitrosomyoglobin, a bright red color compound, which is heat stable (Heinz \& Hautzinger, 2007). Mechanism of development of characteristic red color in meat after addition of nitrite is shown in the Figure 1 (Belitz, Grosch, \& Schiebierle, 2009).

In addition to this effect, nitrite has certain inhibitory effect on growth of bacteria, attributes to desire curing flavor and stabilizing action against fat (Heinz \& Hautzinger, 2007). 5$20 \mathrm{mg}$ of nitrite per $\mathrm{kg}$ is considered sufficient for red color development whereas, $50 \mathrm{mg}$ per $\mathrm{kg}$ is required to develop the characteristics taste and $100 \mathrm{mg}$ per $\mathrm{kg}$ to have antimicrobial effect (Belitz, Grosch, \& Schiebierle, 2009). However, nitrite is considered as a precursor of carcinogenic compounds like nitrosamines and has also been related to increased risks of gastric, esophageal, nasopharyngeal and bladder cancers (Zhang, Sun, Han, Zhang, \& Hou, 2017). Because of this food safety aspect, usage of nitrite in meat products is regulated by law. Mandatory Food Standards of Nepal (DFTQC, 2016) and Food Safety Standard of India (FSSAI, 2011) both have allowed a maximum of 200 ppm of sodium nitrite in meat and meat products. Similarly, European Union has set the maximum limit of $150 \mathrm{mg}$ per $\mathrm{kg}$ of nitrites in non-heattreated and heat-treated (Except sterilized meat products) meat products (European Commission , 2011). However, Codex Alimentarius has limited the residual nitrite content as $80 \mathrm{mg} / \mathrm{kg}$ in processed comminuted meat, poultry and game products (Codex Alimentarius, 2017).

Different methods have been used to determine nitrites and nitrates in food products. However, extraction of nitrites and nitrates from the food matrix is vital for their determination. Siddiqui, Wabaidur, Khan, Alothman, Rafique, \& Alqadami, (2018) and Hsu, Arcot, \& Lee, (2009) had extracted nitrite from the sample by subsequent procedures of homogenization, heat treatment, centrifugation, filtration and injection in high pressure liquid chromatography for the estimation. However, Adam, Mustafa, \& Rietjens, (2016) and Leth, Fagt, Nielsen, \& Anderson, (2008) had heated the mixed sample, precipitated the protein by adding Carrez I and II solutions, developed a color using sulphanilamide and N- (1napthyl)-ethylene-diammonium chloride and measured spectrophotometrically at $540 \mathrm{~nm}$. Other researchers have used cyclic voltammetric (Yildiz, Oztekin, Orbay, \& Senkal, 2014), capillary electrophoresis (Oztekin, Nutku, \& Erim, 2002) and ion chromatography with UV detector (Siu and Henshall, 1998) method for detection of nitrite and nitrate in meat, meat and vegetable products.

So far in our knowledge, there hasn't been any research on the nitrites in the meat and meat products. The aim of this study is to find the status of nitrites in meat and meat products available in the market of Kathmandu, Nepal. 


\section{Materials and methods Sample collection}

Samples of meat products brought by customers in National Food and Feed Reference Laboratory from July 2017 to June 2018 were used for analysis. 64 samples available in the laboratory were analyzed among which, 62 products were from Nepal and two products were from the People's Republic of China. The samples were classified into five categories namely buff sausages, chicken sausages, others (pork/fish/mutton) sausages, ham/bacon/salami/cold cut, and miscellaneous products (meat pickles, dried meat, mo:mo, kebab). Sample distribution is shown in the Table 1.

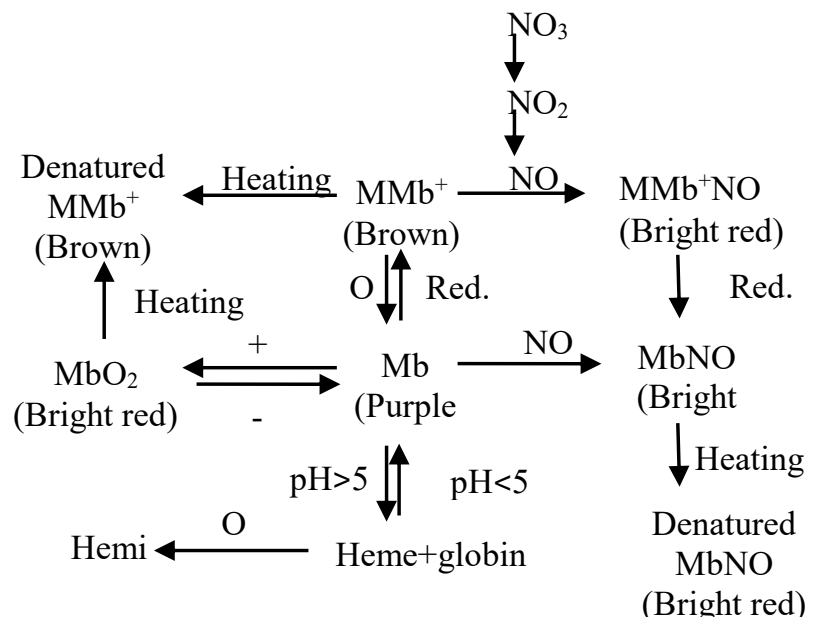

Figure 1. Myoglobin reactions (Mb: myoglobin, $\mathrm{MMb}^{+}$: metmyoglobin, $\mathrm{MbO}_{2}$ : oxymyoglobin, $\mathrm{MbNO}$ : nitrosylmyoglobin, $\mathrm{MMb}+\mathrm{NO}$ : nitrosylmetmyoglobin) (Belitz, Grosch, \& Schiebierle, 2009).

Materials UV-Vis spectrophotometer (Thermo, Genesys 10UV, USA), centrifuge (MPW-260, MPW MED. Instruments, Poland), water bath, centrifuge tubes, sodium nitrite standard (Sigma-Aldrich, purity: 99.999\%), N-(1Napthyl) ethylenediamine.2HCl (NED, AR grade), sulphanilamide (AR grade), acetic acid (AR), distilled water were used for the analysis.

Method Determination of nitrites in meat samples were performed following AOAC (2016), $20^{\text {th }}$ edition (Method no. 973.31) with slight modification. Briefly, approximately $5 \mathrm{~g}$ of minced sample was mixed with hot water and transferred into $100 \mathrm{ml}$ volumetric flask, which was then heated in water bath $\left(80^{\circ} \mathrm{C}\right)$ for two hours with occasional shaking. The sample was cooled, volume was made up and was centrifuged at $6000 \mathrm{rpm}$ for 10 minutes. $5-10 \mathrm{ml}$ aliquot was taken in 50 $\mathrm{ml}$ volumetric flask and sulphanilamide and NED reagents were added to develop the color. Absorbance was measured at $540 \mathrm{~nm}$ after 15 minutes against reagent blank using UVVis spectrophotometer. Calibration curves (0.0-1.0 ppm) were drawn for every lot of analyzed samples as shown in Figure 2. A regression coefficient $\left(\mathrm{R}^{2}\right)$ value of 0.997 to 1.0 was achieved. Each sample was analyzed in triplicate.

Results were expressed as $\mathrm{NaNO}_{2}$ in ppm. Values are shown in term of mean, estimated standard error of the estimated mean, minimum and maximum value.

\section{Data analysis}

MS Excel and SPSS Statistics 21 were used for data analysis. Descriptive analysis and analysis of variance, two-sample ttest were performed for statistical analysis. Statistical analysis was performed at 5\% level of significance.

\section{Limit of detection (LOD) and limit of quantification (LOQ)}

LOD and LOQ of the spectrophotometer were calculated from calibration curve following the International Conference on Harmonization guideline (ICH Guideline, 1994). Formulas for calculation are given below.

$$
\begin{aligned}
& \text { a. Limit of Detection (LOD) }
\end{aligned}
$$

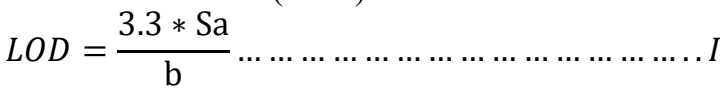

$$
\begin{aligned}
& \text { b. Limit of Quantification (LOQ) }
\end{aligned}
$$

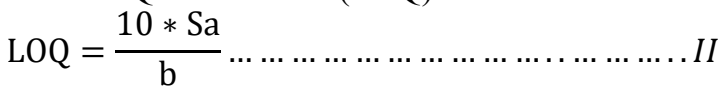

where, $\mathbf{S a}$ is the standard deviation of the response and $\mathbf{b}$ is the slope of the calibration curve. The standard deviation of the response was estimated by the standard deviation of $y$ residuals of regression lines.

\section{Recovery Test}

Recovery test was performed in the chicken and buff sausages. Stock solution of $400 \mathrm{ppm} \mathrm{NaNO}_{2}$ was used for spiking procedure. Spiking was performed at 50, 100 and 200 ppm level. Analysis was done following the procedure mentioned in the method section.

Percentage recovery was calculated as below.

$\%$ Recovery $=($ Observed - Neat $) \times 100 /$ Expected $\ldots . . . I I I$

where, Observed: Observed concentration in the spiked sample.

Neat: Observed concentration in the unspiked sample.

Expected: Expected concentration in the spiked sample (calculated based on assigned concentration of spiking stock and volume spiked into sample).

\section{QA/QC sample analysis}

Quality control sample of meat product was also analyzed to verify the results of the research work. The QC sample (Reference no. T15126QC) was bought from Fera Science Ltd (Fera) Sand Hutton, York, YO41 1LZ. Sample was kept under $-18^{\circ} \mathrm{C}$ until analysis.

\section{Results and Discussion \\ Sample analysis}

Sodium nitrite content in 64 meat and meat products are shown in Table 1. None of the samples has exceeded the limit of $\mathrm{NaNO}_{2}$ (200 ppm) set by Government of Nepal and India. However, approximately five percent $(\mathrm{N}=3)$ of the samples had crossed the European Union standard (150 ppm).

Highest range (1.49-165.72 ppm) of sodium nitrite was found in chicken sausages and lowest (Not detected-55.83 ppm) in miscellaneous products (meat pickle, mo:mo, kebab, dried meat, and claws). There is the possibility that the value of $\mathrm{NaNO}_{2}$ of the products can also be supplemented by the 
natural nitrites present in meat and other ingredients. Since nitrite can readily oxidize to nitrate due to presence of sequestering oxygen, nitrite content in the products can be affected due to conversion of nitrite into nitrate (Honikel, 2008). Merino, Darnerud, Toldra, \& Ilback (2016) noted that nitrite was decrease faster for 24 hours after addition of nitrite during the storage of the meat products. No study was conducted so far on the presence of nitrite from natural sources in meat and meat products in the market of Nepal. So, there is no cut off value of $\mathrm{NaNO}_{2}$ to consider whether the obtained value of $\mathrm{NaNO}_{2}$ is residual. Different researchers had considered different residuals values for different types of meat and meat products.

Mean residual values of 0.1 to $12.2 \mathrm{ppm}$ of nitrite in different category of conventional cured meat products were reported by (Gonzalez, et al., 2012). Iammarino \& Taranto (2012) did not find nitrites in fresh meat (LOQ value of $4.5 \mathrm{ppm}$ ) in their study. Similarly, Hsu, Arcot, \& Lee, (2009) did not observed naturally presented nitrite in beef. Based on literature, this research considers $10 \mathrm{ppm}$ of $\mathrm{NaNO}_{2}$ as residual amount for data analysis.

Table 1 shows that all the buff sausages and ham/bacon/salami/cold-cut contained added $\mathrm{NaNO}_{2}$. This indicates that the use of $\mathrm{NaNO}_{2}$ is common in these kinds of products. Similarly, $90 \%$ of chicken sausages and $67 \%$ of other sausages (pork/fish/mutton) contained added $\mathrm{NaNO}_{2}$. Meat $(\mathrm{N}=5)$ contain $\mathrm{NaNO}_{2}$ lower than 10 ppm (Data not shown) indicating the use of $\mathrm{NaNO}_{2}$ in this kind of miscellaneous meat products is still not common.

\section{Table1}

Sample distribution and $\mathrm{NaNO}_{2}$ content in different meat products.

\begin{tabular}{lcc}
\hline Type of Meat & No. of & NaNO2, in ppm \\
Product & Sample & \\
\cline { 3 - 3 } & & Average \pm Standard error \\
\hline Buff Sausage & 19 & $\begin{array}{c}72.42 \pm 11.70 \\
(14.83-159.70)\end{array}$ \\
& & $56.70 \pm 9.27$ \\
Chicken Sausage & 19 & $(1.49-165.72)$ \\
\hline Other sausage & 6 & $44.17 \pm 17.33$ \\
& & $(2.55-114.97)$ \\
\hline Bacon/Ham/ & 11 & $47.22 \pm 7.36$ \\
Salami & & $(10.37-87.59)$ \\
\hline Miscellaneous & 9 & $13.72 \pm 6.24$ \\
& & $\left(\right.$ N.D. $\left.{ }^{*}-55.83\right)$ \\
\hline Total & 64 & \\
\hline
\end{tabular}

"N.D. indicates not detected, values in the parentheses are minimum and maximum value of $\mathrm{NaNO}_{2}$.

Meat pickles and dried meat are the common Nepali products, which have comparatively higher self-life and do not need to add nitrite for color development. This might be the reason for low nitrite in these products. In other four miscellaneous products: chicken claw, chicken mo:mo, chicken Sheikh Kebab and prawn achar, contain higher than 10ppm of $\mathrm{NaNO}_{2}$, which can be the outcome of added $\mathrm{NaNO}_{2}$ or can be due to presence of nitrite in other ingredients.
Among the five types of meat products, greater interference was found in buff sausages. During the triplicate analysis of buff samples following the same procedure at the same time, pink color did not developed in some of the triplicates. However, such interferences did not occur in other meat products. Wootton, Kok \& Buckle (1985) had also observed similar matrix interference during the analysis of meat and meat products.

\section{Limit of detection (LOD) and limit of quantification (LOQ)}

LOD and LOQ of the spectrophotometer were calculated as 0.0076 and $0.023 \mathrm{ppm}$. This indicates that the instrument used was sensitive to determine $\mathrm{NaNO}_{2}$ in the samples with the given mandatory standard of Nepal Government.

\section{Recovery test}

Percentage recoveries of $\mathrm{NaNO}_{2}$ after spiking in chicken and buff sausage are shown in the Table 2 . The recovery percentages were found in the range of $80-120 \%$. However, overall recovery percentages were significantly higher in buff sausage $(103.40 \pm 3.57 \%)$ than in chicken sausage $(89.75 \pm$ $4.79 \%)$ at $5 \%$ level of significance $(\mathrm{p}=0.000)$.

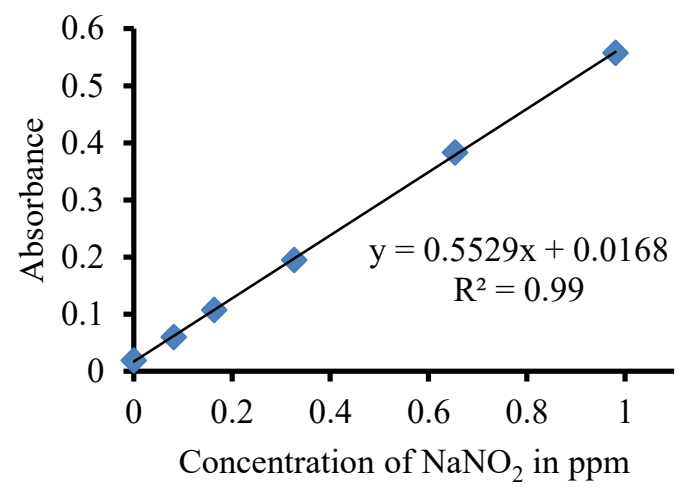

Figure 2. Calibration curve of sodium nitrite.

It was also found that recoveries were lowest when spiked at 50 ppm among the three concentrations in chicken sausage. Recoveries were significantly different at the three concentrations in case of chicken sausage while there was no significant difference in buff sausage. Yildiz, Oztekin, Orbay, \& Senkal (2014) had found recovery of $98-103 \%$ in salami, sausage and bologna.

\section{Table 2}

Recovery test of $\mathrm{NaNO}_{2}$ after spiking in chicken and buff sausage at different concentration.

\begin{tabular}{ccc}
\hline \multirow{2}{*}{$\begin{array}{c}\text { Spiking } \\
\text { concentration } \\
(\mathrm{ppm})\end{array}$} & \multicolumn{2}{c}{$\begin{array}{c}\text { Recovery percentage } \\
\pm \text { standard deviation }\end{array}$} \\
\cline { 2 - 3 } & Chicken sausage & Buff sausage \\
\hline 50 & $84.32 \pm 1.91^{\mathrm{a}}$ & $99.84 \pm 2.57^{\mathrm{x}}$ \\
\hline 100 & $94.97 \pm 0.89^{\mathrm{b}}$ & $104.36 \pm 3.12^{\mathrm{x}}$ \\
\hline 200 & $89.97 \pm 1.57^{\mathrm{c}}$ & $105.99 \pm 2.04^{\mathrm{x}}$ \\
\hline Overall recovery & $89.75 \pm 4.79^{\mathrm{p}}$ & $103.40 \pm 3.57^{\mathrm{q}}$ \\
\hline
\end{tabular}

Different superscripts for different spiking concentrations indicate difference at $5 \%$ level of significance 
Analysis of variance was performed separately for chicken and buff sausage. Overall recovery was compared using twosample t-test. Similarly, Hsu, Arcot, \& Lee (2009) recovered 80 to $109 \%$ in cured and fresh meat. Type of meat source, magnesium, calcium and iron from other ingredients and reactive nature ofnitrite itself can be the reason for the variation in recoveries (Hsu, Arcot, \& Lee, 2009).

\section{Quality control sample analysis}

In the QC sample, concentration of NaNO2 was $162.5 \pm 1.08$ ppm, which was within the range given by the supplier (138$226 \mathrm{mg} / \mathrm{kg}$ ) and was within the limit of $\pm 2 \mathrm{z}$-scores. This indicates that the analysis preformed in the laboratory was satisfactory.

\section{Conclusions}

Consumption of meat and meat products are increasing day by day in Nepal. Added sodium nitrite in meat products for color development and antimicrobial purpose has several health effects in human. Sodium nitrite in meat and meat products available in Kathmandu valley was estimated in this study. Among the 64 samples analyzed, none of the samples exceeded the maximum value set by Government of Nepal and India. However, five percent of the total samples had crossed the European Union standard. The highest range of Sodium nitrite was found in chicken sausages (1.49-165.72 ppm) whereas the lowest in miscellaneous products (Not detected-55.83 ppm). It was found that all the buff sausages, ham, bacon, salami and cold-cut contained added $\mathrm{NaNO}_{2}$. However, this was not the case in chicken and pork sausages and miscellaneous products. The recoveries in both chicken and buff sausages at 50, 100 and $200 \mathrm{ppm}$ of spiking were $84.32,94.97,89.97 \%$ and $99.84, \quad 104.36, \quad 105.99 \%$ respectively. The overall recovery was significantly higher in buff sausage $(103.40 \pm 3.57 \%)$ than in chicken sausage $(89.75$ $\pm 4.79 \%)$.

\section{References}

Adam, A. H., Mustafa, N. E., \& Rietjens, I. M. (2016). Nitrite in processed meat products in Khartoum, Sudan and dietary intake. Food Additives \& Contaminants: Part B

Codex Alimentarius Commission (2017). General Standard for Food Additives CODEX STAN 192-1995. Codex Alimentarius. Retrieve from http://www.fao.org/faowho-codexalimentarius/codex-texts/list-standards/en/.

AOAC. (2016). Official Method of Analysis, Association of Official Analytical Chemists. 16th edition Washington, DC, USA.

Belitz, H., Grosch, W., \& Schiebierle, P. (2009). Food Chemistry. Springer.

CBS. (2015). Statistical Year Book. Kathmandu: Central Bureau of Statistics.

Commission, E. (2011). Commission Regulation (EU) No 1129/2011 amending Annex II to regulation (EC) No $1333 / 2008$ of the European Parliament and of the Council by establishing a union list of food additives.Retrieve from https://eur-lex.europa.eu/legalcontent/EN/TXT/?uri=CELEX:32011R1129. Off. J. Eur Union. .

DFTQC. (2016). Minimum Mandatory Standard for Food and Feed Products. Kathmandu: Department of Food Technology and Quality Control.
FSSAI. (2011). Food Safety and Standards (Food Products Standards and Food Additives) Regulations. India: Food Safety and Standard Authority of India. Retrieve from https://www.fssai.gov.in/cms/food-safety-andstandards-regulations.php.

Gonzalez, M. T., Osburn, W. N., Hardin, M. D., Longnecker, M., Garg, H. G., Bryan, N. S. \& Keeton, J.T.(2012). Survey of residual nitrite and nitrate in conventional and organic/natural/uncured/indirectly cured meats available at retail in the United States. Journal of Agricultural and Food Chemistry , 60, 39813990.

Guideline, I. H. (1994). Validation of Analytical Procedures: Text and Methodology Q2 (R1). Retrieve from https://database.ich.org/sites/default/files/Q2_R1_ Guid eline.pdf.

Heinz, G., \& Hautzinger, P. (2007). Meat Processing Technology. Bangkok, Thailand: FAO.

Honikel, K.-O. (2008). The use and control of nitrate and nitrite for the processing of meat products. Meat Science , 68-76.

Hsu, J., Arcot, J., \& Lee, N. A. (2009). Nitrate and nitrite quantifiation fron cured meat and vegetables and their estimated dietary intale in Australians. Food Chemistry, 334-339.

Iammarino, M., \& Taranto, A. D. (2012). Nitrite and nitrate in fresh meat: a contribution to the estimation of admissible maximum limits to introduce in directive 95/2/EC. International Journal of Food Science and Tchnology, 1-7.

Leth, T., Fagt, S., Nielsen, S., \& Anderson, R. (2008). Nitrite and nitrate content in meat products and estimated intake in Denmark from 1998 to 2006. Food Additives \& Contaminants: Part A , 1237- 1245.

Merino, L., Darnerud, P. O., Toldra, F., \& Ilback, N.-G. (2016). Time-dependent depletion of nitrite in pork/beef and chicken meat products and its effect on nitrite intake estimation. Food Additives \& Contaminants: Part A, 186-192.

Oztekin, N., Nutku, M. S., \& Erim, F. B. (2002). Simultaneous determination of nitrite and nitrate in meat products and vegetables by capillary electrophoresis. Food Chemistry, 103-106.

Siddiqui, M. R., Wabaidur, S. M., Khan, M. A., Alothman, Z. A., Rafique, M. Z., \& Alqadami, A. A. (2018). A rapid and sensitive evaluation of nitrite content in Saudi Arabian processed meat and poultry using a novel ultra performance liquid chromatography-mass spectrometry method. J Food Sci Technol, 198-204.

Wootton, M., Kok, S., \& Buckle, K. A. (1985). Determination of Nitrite and Nitrate level in Meat and Vegetable products by High Performance Liquid Chromatography. Journal of Science, Food and Agriculture , 36, 297-304.

Yildiz, G., Oztekin, N., Orbay, A., \& Senkal, F. (2014). Voltammetric determination of nitrite in meat products using polyvinylimidazole modified carbon paste electrode. Food Chemistry, 245-250.

Zhang, H., Sun, C., Han, W., Zhang, J., \& Hou, J. (2017). Analysis the monitoring status of residual nitrite in meat products in China from 2000 to 2011. Meat Science. 